\section{Visual signal processing: A function of key difference-letter space location}

M. E. TRESSELT and BARBARA HUGO, New York University, New York, N.Y. 10003

Using a paradigm developed earlier, $S s$ were presented with two lines of six words each and were required to detect a target word common to both lines. There were three conditions: Condition $A$ had all words, including the target word, starting with the same letter; Condition $B$ had all the last letters the same; and Condition $C$ had all words beginning and ending with different letters. These conditions produced significantly different reaction times, the slowest being found for Condition A.

It is not unusual that an individual be asked to search the telephone directory for a specific name, to go through a checkbook to locate a certain check that has been sent and to ascertain its amount, or to do any number of tasks that involve information-processing operations. If there were only one check that you had ever written, the task of search would be elementary; if there were several checks, but only one to the specific firm or person concerned, the problem would be a little more complex; and if there were many checks to the same specific firm or person, the process of analyzing the information would be even more time-consuming.

Neisser, Novick, \& Lazar (1963) presented to their Ss the task of searching and locating specific single or multiple letters embedded in random letter lists. As one of their findings, they reported that one of the time expenditures inherent in this type of research is related to the position in the list of letters of the target or targets. If it is known that there is one $\mathrm{K}$ and if it occurs in the first set of letters, there is no need to go further in the list if it has been found; if it is three-quarters through the list, it will take that much longer to be found.

For this reason and others, Mayzner, Tresselt, \& Pezenik (1968), using a tachistoscope, exposed to Ss two lines of 10 letters and required the $S$ to detect a target letter common to both lines. The $S$ was given $2,4,6$, or $8 \mathrm{sec}$ to locate the target. In another condition, they presented the $S$ with two lines to identify the common letter, but there were actually two sets of common letters present. They varied the target positions over the 10 positions in the top and bottom rows. The results show that (1) an increase from one to two targets almost doubles the number of correct detections, and (2) the greater the time, the greater the number of correct identifications.

Neisser (1964) also introduced more complicated tasks wherein he required Ss to look for a word in terms of its meaning, e.g., the name of an animal. If he had indicated that the animal in question started with $\mathrm{L}$, the search could well have become a search for a single letter. How would the search time have been affected if all the irrelevant words began with an $L$ ?

Without considering the factor of meaning, it was decided to investigate the part played by letter similarity and placement, i.e., location at the beginning and end of three-letter words. \section{METHOD}

The Ss were 20 undergraduate students from the Psychology Department of New York University.

The basic task consisted of a card being displayed to the $S$ in a Gerbrands one-field tachistoscope, on which two lines of sixand three-letter words appeared, one line directly below the other, with all letters in caps. The $S$ was instructed to lift his finger from a response key as soon as he could identify the word that was common to both lines. A Hunter timer initiated the exposure, and a record was made of the time needed for a correct response. A total of 75 cards were prepared; 25 cards (Condition A) consisted of words where the first letter was the same, e.g., fat, fog, fur, fix, fed, fan, etc., 25 cards (Condition B) consisted of words where the last letter was the same, e.g., jog, dig, rug, peg, etc., and there were 25 words (Condition C) where the letters were all different, beginning and end.

\section{RESULTS AND DISCUSSION}

Table 1 presents the major results showing the median times for identifying the target under the three experimental conditions. A Friedman two-way analysis of variance by ranks test (Siegel, 1956, pp. 166-172) yielded a $\chi_{I}^{2}=9.30, \mathrm{df}=2$, $\mathrm{p}<.01$; the greatest amount of time taken was when the beginning letters were all alike, and the shortest time is found when the first letters were all different. Since both Condition B and Condition C had different beginning letters and only the last letters in Condition B were alike, there seems to be little attention paid to the last letter in a series of three-letter words.

The target locations were relatively equalized over the six positions in the top and bottom lines, with the constraint that the target location on each line always be separated by at least two other nontarget words. Thus, target words that fell in the left half of the first line always were matched on the right half of the second line; for example, a word, ACT, found in the first position in the first line appeared in the fourth position of the second line, or CUD appeared in the first position in the first line and in the sixth position in the second line, or BUS occurred as the fifth word in the first line and as the second word in the second line, and so forth. Although the differences are small, they are all in the same direction. Those words in the first half of the upper line and in the last half of the lower line were recognized faster than the combination of first line-last half and second line-first half.

A closer inspection of Condition A, where all words started with the same letter, poses some question for future research. Since all words were printed in caps, there was little change of patterns being identified in terms of attributes in the same way as they might be if they had letters above and below a line as in script writing. What made for the variations from a median reaction time of 3.00 to 10.38 (see Table 2)?

The fastest time was found for a stimulus card with the following content:

\section{DUO DRY DOT DEW DIE DOG DAB DID DIP DEN DUO DIM}

Duo is the key word. It could be argued that this word is an infrequent one and ends in a unique $o$, which is an infrequent

Table 1

Median Times (in Secs) for Condition A (First Letter Same), Condition B (Last Letter Same) and Condition C (All Letters Different)

\begin{tabular}{lccc}
\hline & $\begin{array}{c}\text { First Half of Array } \\
\text { (First Line) }\end{array}$ & $\begin{array}{c}\text { Second Half of Array } \\
\text { (First Line) }\end{array}$ & $\begin{array}{c}\text { Overall } \\
\text { Total }\end{array}$ \\
\hline Condition A & 5.27 & 5.71 & 5.54 \\
Condition B & Range: $1.83-7.41$ & Range: $3.20-10.42$ & Range: $3.50-8.66$ \\
& 3.82 & 5.01 & 4.67 \\
Condition C & Range: $1.26-8.60$ & Range: $2.98 \cdot 9.87$ & Range: $3.21-7.39$ \\
& 3.44 & 4.50 & 4.26 \\
& Range: $1.40-8.83$ & Range: $2.92-8.90$ & Range: $2.55-6.43$ \\
\hline
\end{tabular}


third letter in a three-letter word starting with d. However, another 3.26 reaction time was found for:

PIG PAN POT PRY PEW PUP

PRO PAD PEA PIG PAR PUS

The correct word is pig. This word is a popular word with relatively high probability of letter frequency. If infrequent words would distract by drawing attention, this card should have produced a slow reaction time.

The 10.38-sec reaction time was obtained for a card with the following:

\section{GAB GEL GOD GUN GIG GET GIG GUM GUY GAS GEE GAP}

To some extent, the long reaction time for this card is probably a function of the placement of GIG in the 5-1 position. In itself, it is not a common word, but it is in the context of another very uncommon one, i.e., GEL. In contrast, one stimulus card with a 3.26 median time occurred in a 6-2 position and contained:

\section{LIP LOW LAC LAY LAB LOG \\ LFI LOG LOT LAD LEE LOP}

Lac, lei, and lee might be classified as relatively uncommon in both language and letter combinations.

Future research will investigate the part played by word frequency and letter

Table 2

Median Reaction Times for Individual Cards (Condition A-First Letter Same)

\begin{tabular}{|c|c|c|c|c|}
\hline \multicolumn{2}{|c|}{$\begin{array}{l}\text { Position of } \\
\text { Search Word }\end{array}$} & \multirow[b]{2}{*}{ Target } & \multirow[b]{2}{*}{$\mathrm{Mdn}$} & \multirow[b]{3}{*}{ Range } \\
\hline $\begin{array}{l}\text { First } \\
\text { Line }\end{array}$ & Second & & & \\
\hline Line & & Word & RT & \\
\hline 1 & 4 & act & 5.24 & $1.08-30.16$ \\
\hline 1 & 4 & rim & 4.63 & $1.21-10.08$ \\
\hline 1 & 4 & pig & 3.26 & $1.19-24.04$ \\
\hline 1 & 5 & nag & 4.09 & $1.05-19.54$ \\
\hline 1 & 5 & duo & 3.00 & $.97-31.53$ \\
\hline 1 & 6 & cud & 5.28 & $1.05-20.89$ \\
\hline 1 & 6 & oil & 5.97 & $1.05-14.41$ \\
\hline 2 & 5 & sob & 6.45 & $2.04-16.58$ \\
\hline 2 & 5 & why & 5.08 & $1.79-32.37$ \\
\hline 2 & 6 & fry & 6.52 & $1.83-16.01$ \\
\hline 2 & 6 & ply & 5.65 & $2.78-41.65$ \\
\hline 3 & 6 & hem & 4.66 & $1.95-29.61$ \\
\hline 3 & 6 & hay & 5.23 & $1.51-15.43$ \\
\hline 4 & 1 & fad & 5.18 & $1.09-19.94$ \\
\hline 4 & 1 & toe & 5.68 & i. $17-18.75$ \\
\hline 5 & 1 & doe & 6.13 & $1.77-15.06$ \\
\hline 5 & 1 & gig & 10.38 & $3.26-29.25$ \\
\hline 5 & 2 & $\mathrm{cab}$ & 6.47 & $3.21-25.71$ \\
\hline 5 & 2 & bus & 7.31 & $1.20-65.49$ \\
\hline 6 & 1 & rut & 5.54 & $1.91-23.71$ \\
\hline 6 & 1 & mug & 5.99 & $1.98-14.14$ \\
\hline 6 & 2 & tug & 6.47 & $2.98-26.94$ \\
\hline 6 & 2 & $\log$ & 3.26 & $1.95-32.62$ \\
\hline 6 & 3 & sag & 5.59 & $1.50-10.60$ \\
\hline 6 & 3 & elf & 6.39 & $3.47-11.67$ \\
\hline
\end{tabular}

frequency. The position of the frequent or nonfrequent words or letter frequencies in relation to the key word should also be investigated. Lei and lee may not even be important as distractors, since they are in the second line in the example above.

It would seem that there may be a simple "template matching," but the content of the array and the formation of the target in relation to the array leads to some degree of facilitation or inhibition of response speed.

\section{REFERENCES}

MAYZNER, M. S., TRESSELT, M. E., \& PEZENIK, J. A study of detection, search. matching, and memory functions. Psychonomic Science, 1968, 10, 217-218.

NEISSER, U. Visual search. Scientific American, $1964,210,94-102$.

NEISSER, U., NOVICK, B., \& LAZAR, R. Searching for ten targets simultancously. Perception \& Motor Skills, 1963, 17, 955-961. SIEGEL, S. Nonparametric statistics for the behavioral sciences. New York: McGraw-Hill 1956.

\section{Short-term temporal stability of interpersonal attraction $^{1}$}

\section{WILLIAM GRIFFITT and PAUL NELSON, Kansas State University, Manhattan, Kans. 66502}

The temporal stability of attitude-evoked attraction responses and the similarity-attraction relationship were examined across a l-week time interval. In the absence of additional information concerning a stranger, attraction toward the stranger was found to be highly stable $(p<.001)$. In addition, the positive relationship between similarity and attraction was found to be quite stable $(p<.01)$ across this time period.

Experimental work on interpersonal attraction (Byrne, 1969) and impression formation (Anderson, 1968) is commonly characterized by a laboratory situation in which Ss are exposed to a series of stimuli attributed to or associated with a target person. Ss are then asked to rate the target person on one or more such evaluative dimensions as attraction, attractiveness, or competency. Under such conditions, investigators have typically examined the relationship between linear combinations of differentially weighted positive and negative stimulus components and initial evaluative impressions or judgments concerning the target person (Griffitt, Byrne, \& Bond ${ }^{2}$ ). Some investigators have attempted to investigate systematic sequential changes in evaluative impressions as a function of sequentially presented attitudinal stimuli and sequential assessment of attraction responses (Byrne, Lamberth, Palmer, \& London, in press) as well as systematic response variability as a function of sequential presentation of adjective stimuli (Stewart, 1965).

The relationship between attitude similarity and attraction is well established.
Attraction toward a stranger is consistently found to be a positive linear function of the proportion of attitudes expressed by the stranger that are similar to those of the S (Byrne, 1969). Little is known, however, concerning either the temporal stability of attraction responses or the temporal stability of the similarity-attraction relationship under conditions in which $S$ is exposed to no additional information concerning the target person. When repeated contact and communication are possible, Newcomb (1961) has reported that attraction stabilizes at relatively early stages of acquaintance, and that the similarity-attraction relationship increases in magnitude over time. On the other hand, Kerckhoff \& Davis (1962) have reported that value similarity and courtship progress were positively related for short-term dating couples but not for long-term dating couples. Levinger \& Breedlove (1966) have attributed the latter finding to the decreasing instrumentality of generalized value consensus in the advanced stages of courtship.

The present investigation was designed primarily to examine the temporal stability of attraction responses and of the similarity-attraction relationship when Ss have no opportunity to acquire additional information concerning the target person. METHOD

The Ss for the experiment were 22 introductory-psychology students at Kansas State University who had been pretested on a 12-item attitude questionnaire similar to those utilized in earlier research (Griffitt \& Byrne, in press). Approximately 2 to 3 weeks following the initial testing, each $\mathbf{S}$ was requested to listen to the tape-recorded responses of an anonymous same-sex stranger to the same attitude questionnaire utilized in 